\title{
METODOLOGIAS ATIVAS: A EXPERIÊNCIA DO CURSO MAES
}

\author{
METODOLOGÍAS ACTIVAS: LA EXPERIENCIA DEL CURSO MAES
}

ACTIVE LEARNING: THE MAES PROGRAM EXPERIENCE

\author{
Conceição de Maria Cardoso COSTA ${ }^{1}$ \\ Azenaide Abreu Soares VIEIRA ${ }^{2}$
}

RESUMO: O texto apresenta o processo de criação e desenvolvimento do Programa MAES: Metodologias Ativas de Aprendizagem para o Estudante do Século XXI, ofertado no Instituto Federal de Mato Grosso do Sul (IFMS) em parceria com pesquisadores do Instituto Federal de Rondônia (IFRO), Instituto Federal de Brasília (IFB), Instituto Federal do Espírito Santo (IFES) e Hame University of Applied Sciences (HAMK). O texto justifica-se tendo em vista que estudos empíricos sobre o efetivo desenvolvimento de currículos baseados em competências são difíceis de encontrar na literatura (KOENEM, 2015), e ainda mais escassas são tais pesquisas em contextos da educação profissional brasileira.

PALAVRAS-CHAVE: Currículo. Transdisciplinaridade. Metodologias ativas.

RESUMEN: El texto presenta relatos del proceso de creación y parte del desarrollo del Programa MAES: Metodologías Activas de Aprendizaje para el Estudiante del Siglo XXI, ofrecido en el Instituto Federal de Mato Grosso do Sul (IFMS), en asociación con investigadores del Instituto Federal de Rondônia (IFRO), Instituto Federal de Brasilia (IFB), Instituto Federal de Espírito Santo (IFES) y Hame University of Applied Sciences (HAMK). El relato se justifica por considerar que estudios empíricos sobre el efectivo desarrollo de currículos basados en competencias son difíciles de encontrar en la literatura (KOENEM, 2015), aún más escasas son tales investigaciones en contextos de la educación profesional brasileña.

PALABRAS CLAVE: Currículum. Transdisciplinariedad. Metodologías activas.

ABSTRACT: The text presents the design process and part of the development of MAES Program: Active Learning Methodologies for the Student of the $21^{\text {st }}$ Century, offered at the Federal Institute of Mato Grosso do Sul (IFMS), in partnership with researchers from

\footnotetext{
1 Instituto Federal de Educação, Ciência e Tecnologia de Brasília (IFB), DF - Brasil. Professorapesquisadora do Programa MAES. Doutora em Geotecnia pela Universidade Federal de Brasília. Participante do Programa VET III - Teachers for the Future. E-mail: conceicao.costa@ifb.edu.br.

2 Instituto Federal de Educação, Ciência e Tecnologia de Mato Grosso do Sul (IFMS), MS - Brasil. Professora Pesquisadora do Programa MAES. Doutora em Estudos Linguísticos pela Universidade Estadual de São Paulo. Participante do Programa VET III - Teachers for the Future e do Programa FiTT - Finnish Training Trainners. E-mail: azenaide.vieira@ifms.edu.br.
} 
the Federal Institute of Rondônia (IFRO), Federal Institute of Brasília (IFB), Federal Institute of Espírito Santo (IFES) and Hame University of Applied Sciences (HAMK). The report is relevant considering that empirical studies on the effective development of competency-based curricula are difficult to find in the literature (KOENEM, 2015), even more scarce are research in Brazilian professional education contexts.

KEYWORDS: Curriculum. Transdisciplinarity. Active methodologies.

\section{Introdução}

Na promoção de Competências Pedagógicas, o desenvolvimento do Saber, do Fazer e do Ser, é considerado um processo dinâmico de combinações de atividades, capaz de desencadear reflexões e ressignificações de práticas pedagógicas de professores, que baseados nos pressupostos da Taxonomia de Bloom (ANDERSON; KRATHWOHL, 2001; FERRAZ; BELHOT, 2010) possam gerar saberes sustentados nos quatro pilares da Educação brasileira, defendidos por Jacques Delors (2003; 2010) , como: Aprender a Conhecer, Aprender a Fazer, Aprender a Conviver e Aprender a Ser.

O primeiro pilar de sustentação, para o autor, é o Aprender a Conhecer. Esse aprender consiste no desenvolvimento da capacidade do indivíduo em compreender que a aprendizagem é contínua e infinita, pois na medida que aprende, emergem novas aprendizagens, e assim sucessivamente.

O segundo pilar é o Aprender a Fazer. Delors (2003) defende que o Aprender a Conhecer e o Aprender a Fazer são indissociáveis, enfoca o desenvolvimento de competências práticas e do trabalho em equipe. À luz da realidade socioeconômica atual, o Aprender a Fazer vai além do simples copiar práticas de outrora. O aprendiz deve estar ciente de que precisa ser capaz de transformar os conhecimentos práticos existentes, gerar inovações e promover avanços na área de atuação.

O terceiro pilar é o Aprender a Conviver. Para Delors (2010) essa aprendizagem é a mais complexa, uma vez que exige da escola mediar o aprendiz na compreensão de si mesmo para, então, compreender as reações do outro. Envolve o respeito pela diversidade e a percepção de que o campo fértil de desenvolvimento humano está nas situações de conflito. Cabe à escola promover a realização de projetos colaborativos com o intuito de preparar o indivíduo para o gerenciamento de conflitos e o desenvolvimento de atitude de empatia, enfatiza Delors (2003). 
O quarto pilar da Educação é o Aprender a Ser. Transformar o Ser Humano e leválo ao desenvolvimento do corpo e da alma é também função da escola. Delors (2003, p. 99) enfatiza que o aprendiz deve evoluir de forma a construir pensamentos críticos e autônomos, para decidir os caminhos a seguir diante de circunstâncias da vida.

Certamente os quatro pilares descritos por Delors (2003; 2010) não se referem apenas ao período e ao espaço escolar. Assim, “[...] os tempos e as áreas da Educação devem ser repensados, completar-se e interpenetrar-se de maneira a que cada pessoa, ao longo de toda a sua vida, possa tirar o melhor partido de um ambiente educativo em constante ampliação" (DELORS, 2003, p. 101).

Diante da importância em se repensar organizações e espaços contemporâneos de aprendizagem escolar foi desenhado, a partir dos pressupostos da Taxonomia de Bloom (FERRAZ; BELHOT, 2010), um programa de formação docente que pudesse atender aos quatro pilares da educação brasileira. Sabe-se que os programas de formação de educadores estão envoltos em muitos desafios, dentre eles o de repensar seus currículos e as concepções educacionais que, implicitamente, sustentam suas práticas. Sendo assim, é emergente construir modelos curriculares que atendam ao perfil da sociedade brasileira contemporânea.

À luz dos princípios da aprendizagem centrada no estudante e a partir da experiência dos educadores, ao participar do Programa VET III - Professores para o Futuro (Vocational Education Training - Teachers for the Future), na Finlândia, foi construído o currículo do programa de capacitação de educadores intitulado MAES: Metodologias Ativas de Aprendizagem centrada no estudante do século XXI (KOENEN; DOCHY; BERGHMANS, 2015). O Programa teve o intuito de promover práticas de formação de educadores no contexto da Educação Profissional Brasileira, com foco no alinhamento de objetivos de aprendizagem (DELORS, 2003; BIGGS, 1996), avaliação (BAARTMAN, 2007) e metodologia (BARBOSA; MOURA, 2013).

Na sequência, a fim de apresentar o processo de criação e o desenvolvimento do Programa MAES, desenvolvido no Instituto Federal de Mato Grosso do Sul (IFMS), campus Nova Andradina, apresenta-se a organização da rede de profissionais responsável pela construção do currículo do Programa, o delineamento do processo de desenvolvimento do currículo, bem como seu percurso prático. 


\section{A equipe: teia que tece teias de ideias}

A proposta do Programa MAES foi desenvolvida de forma colaborativa e em rede por um grupo de quatro (4) professores-pesquisadores de distintos Institutos Federais de Educação Profissional, motivados por reflexões desencadeadas pela realização do programa de formação de professores VET (Vocational Educational and Training), Professores para o Futuro, realizado em parceria pela Secretaria de Educação Profissional SETEC/MEC e duas universidades de ciências aplicadas da Finlândia - TAMK e HAMK. Após três meses de imersão no sistema educacional finlandês, este grupo de professores desafiaram-se a pensar alternativas de intervenções em seus espaços de atuação no Brasil, surgindo a proposta do MAES. Os professores envolvidos inicialmente no projeto atuam em quatro Institutos Federais, localizados em: Mato Grosso do Sul, Brasília, Espírito Santo e Rondônia.

O objetivo do Programa é promover a formação de professores para atuação pedagógica no cenário educacional que se reconfigura com a proposta do Novo Ensino Médio, principalmente no que concerne à adoção de metodologias ativas, cuja aprendizagem é centrada no estudante e norteada por um currículo flexível, baseado nos princípios do desenvolvimento de competências, tomando como parâmetro o modelo educacional finlandês, com rearranjos para atender a realidade da Educação Profissional Brasileira.

Para a oferta do Programa MAES no IFMS, campus Nova Andradina, além da equipe de professores idealizadores do programa, tidos como formadores online, organizou-se uma equipe de professores-formadores local composta por seis (6) profissionais, sendo dois (2) estudantes do curso técnico em informática integrado ao ensino médio, dois (2) professores da rede estadual de ensino, um (1) professor da rede municipal e um (1) professor da rede federal, esse atuando como coordenador local do Programa e como professor-formador local e online. Foram ofertadas quarenta (40) vagas, e o curso ocorreu em dois dias e horários distintos: às segundas-feiras e quartas-feiras, no período noturno, e às terças-feiras e quintas-feiras, no período vespertino.

\section{O processo que se procede e mantém-se em processamento}

Convém esclarecer que o programa MAES foi organizado a partir da pedagogia de projetos, Project Based Learning - PBL. Para Markham (2012), a Aprendizagem Baseada 
em Projeto (ABP) ocorre quando formadores misturam instruções, construção de habilidades e fundamentos do desempenho humano, em uma poderosa metodologia de projeto. $\mathrm{O}$ humanismo se concentra na liberdade, dignidade e potencial humano e acredita que as pessoas agem intencionalmente com base em seus valores pessoais. Esta teoria sugere que a aprendizagem ocorre porque o professor-formador tem um objetivo de aprendizagem específico, atuando como facilitador e/ou orientador e não como detentor único do saber (HUITT, 2009).

Para melhor compreensão do Programa MAES quanto à abordagem teóricametodológica baseada em projeto, segue uma representação analógica do currículo do curso com a estrutura física de uma árvore (Figura 1).

Figura 1: Estrutura do Currículo MAES.

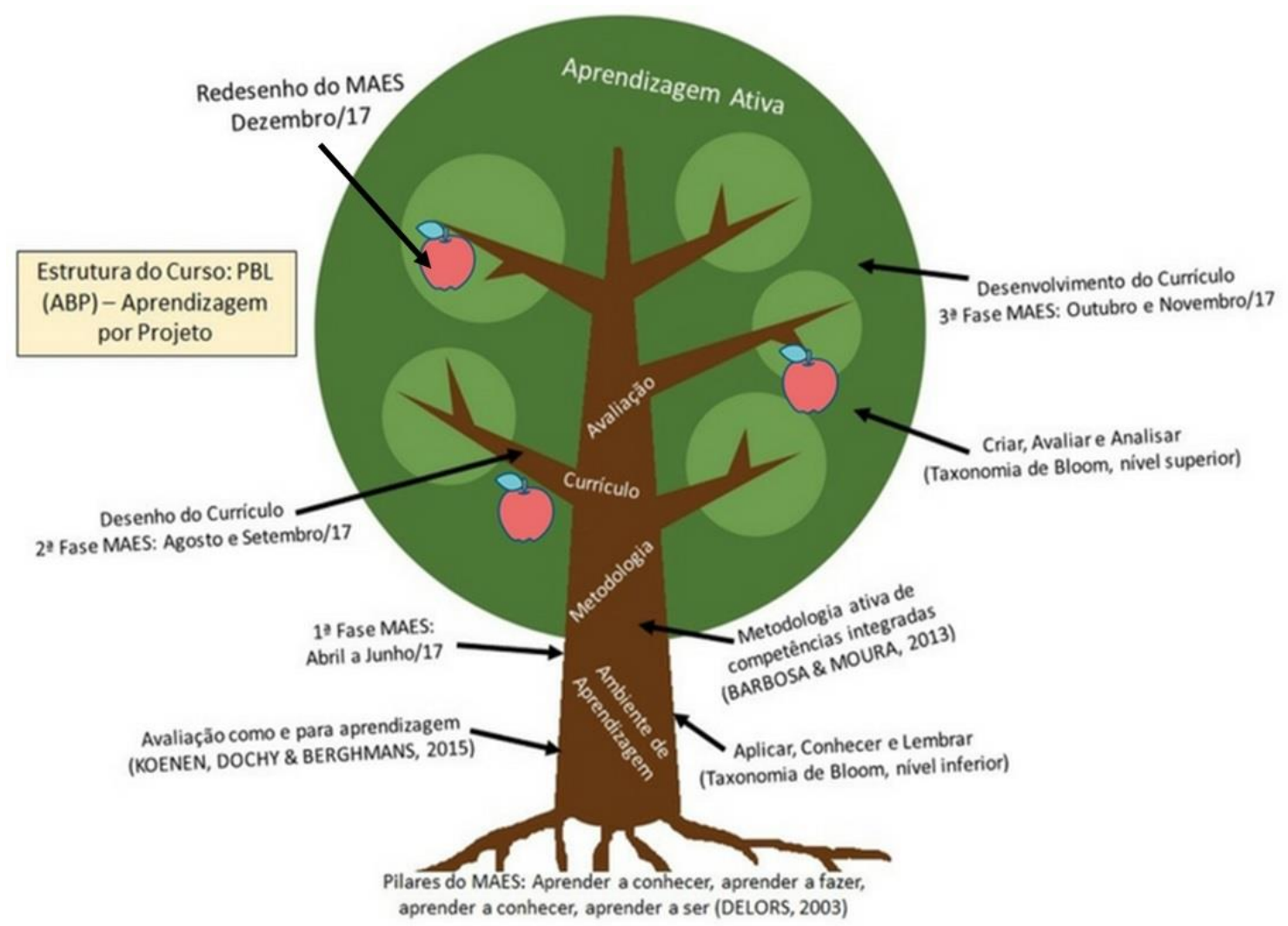

Fonte: Autoria própria.

A base do Programa, raízes da árvore, é construída a partir dos quatro pilares da Educação apresentados por Jacques Delors (2003): Aprender a Conhecer, Aprender a Fazer, Aprender a Conviver e Aprender a Ser. Os temas abordados na primeira fase do curso - Ambiente de Aprendizagem, Metodologia, Currículo, Avaliação - são norteados pelos princípios de lembrar, conhecer e aplicar, nível inferior da Taxonomia de Bloom. Na 
árvore do currículo MAES, essa fase é representada pelo tronco, que dá sustentabilidade ao desenvolvimento da segunda e da terceira fase. Nessas fases do Programa MAES, os professores-cursistas são instigados a avançar para o nível superior da Taxonomia de Bloom - analisar, avaliar e criar. Para isso, são orientados na construção e desenvolvimento de projetos de intervenção nos espaços de atuação, com o objetivo de gerar novos frutos e novas reflexões que sustentarão a reestruturação do Programa MAES, mantendo assim o processo que se procede e mantém-se em processamento, na dinâmica contínua e infinita do aprender.

\section{O conceito norteador do currículo MAES}

Acrescenta-se que os objetivos de aprendizagem vinculados a cada tema Ambiente de Aprendizagem, Metodologia, Currículo, Avaliação - foram construídos com base em competências, a partir dos pressupostos de Perrenoud (1999, 2000, 2001) e Baartman et al. (2007). Assim como Perrenoud, compreende-se competência como a capacidade de mobilizar um conjunto de recursos cognitivos para enfrentar, com pertinência e eficácia, uma série de situações reais. Em outras palavras, competência é entendida como uma integração de conhecimentos, habilidades e atitudes para gerenciar situações emergentes nas relações sociais (BAARTMAN et al, 2007).

Somada às ideias dos autores, apropria-se ainda da definição estabelecida pela Organização para a Cooperação e Desenvolvimento Econômico (OECD, 2016, p. 2) em que competência é "a capacidade de mobilizar conhecimento, aptidões, atitudes e valores, incluindo uma abordagem reflexiva dos processos de aprendizagem, de modo a envolverse e atuar no mundo". A figura 2 apresenta o quadro conceitual da OECD da educação para 2030.

Figura 2: Quadro conceitual da OECD da educação para 2030.

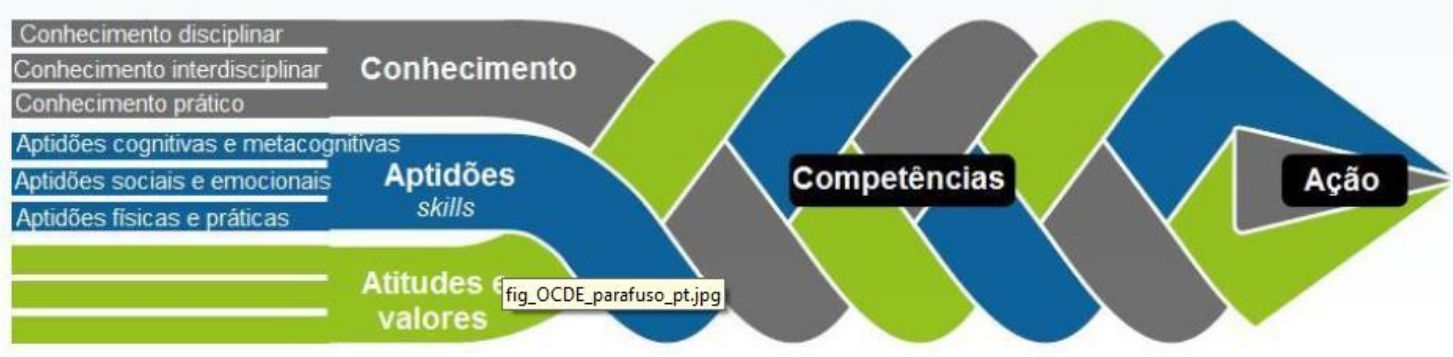

Fonte: OECD (2016) - Modificado.

RIAEE - Revista Ibero-Americana de Estudos em Educação, Araraquara, v. 13, n. esp1, p. 553-563, maio 2018. E-ISSN: $1982-5587$. 
Observa-se na figura 2, a teia que se constitui na atuação por competências, formadas por Conhecimento (disciplinar, interdisciplinar e prático), Aptidões (cognitivas e metacognitivas, sociais e emocionais, físicas e práticas), Atitudes e Valores, constituindo, como no currículo do Programa MAES, um emaranhado de conhecimentos que ultrapassam os limites estabelecidos pelo currículo tradicional, organizado por disciplinas.

Segue descrição detalhada do currículo do Programa MAES, assim como o entrelaçamento na prática das teorias que o sustenta.

\section{O MAES: uma árvore de transformação de saberes docentes}

O currículo do Programa MAES foi estruturado em três fases: 1. aprendizagem baseada em situação problema; 2. planejamento de projeto de intervenção; e 3. desenvolvimento, apresentação de resultados e visitas, totalizando 180 horas de atividades teóricas e práticas. Na figura 3, procura-se facilitar a compreensão quanto à organização, metodologia, período de realização e carga horária do Programa.

Figura 3: Organização do currículo, metodologia, período de realização e carga horária.

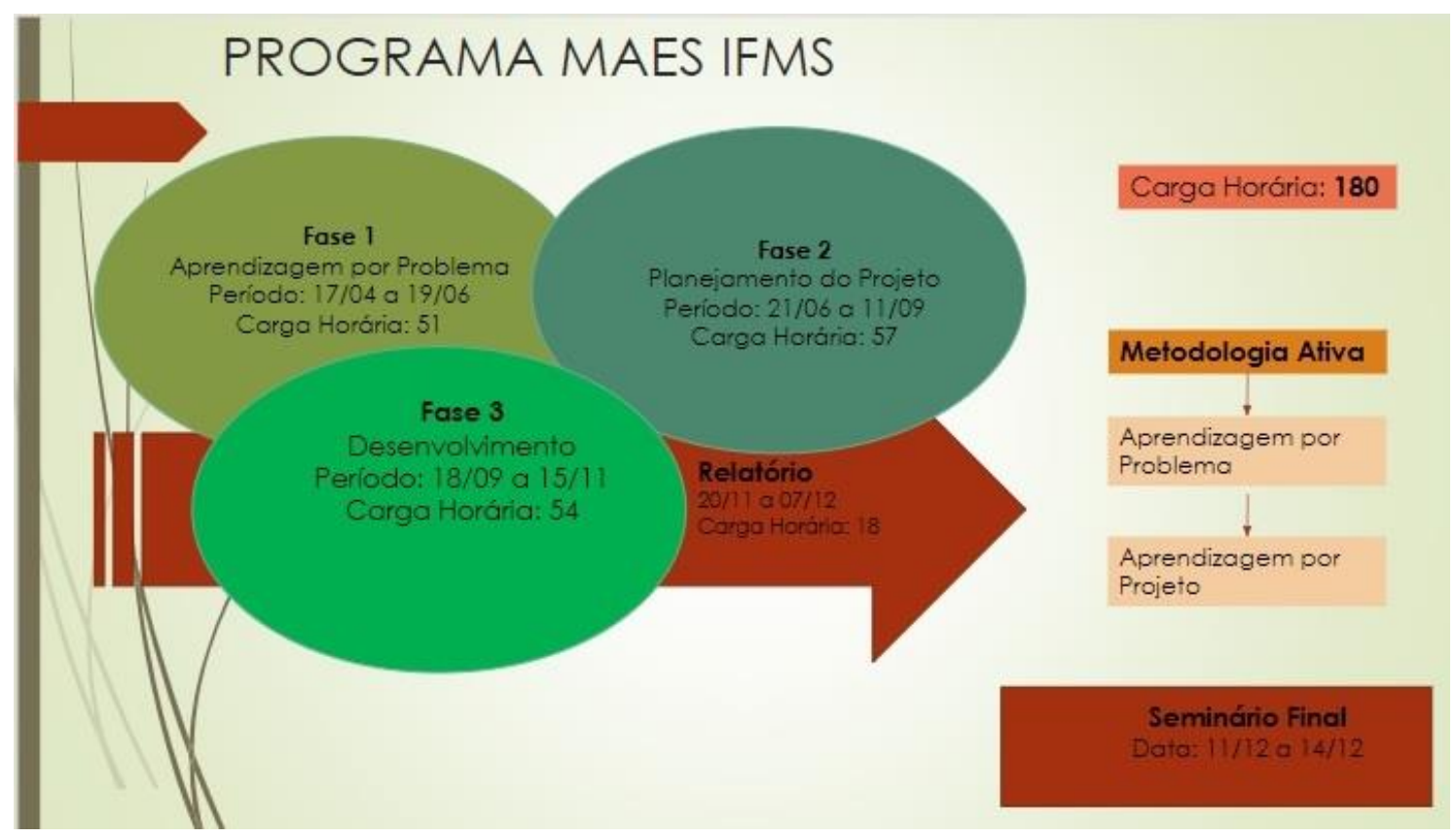

Fonte: Autoria própria. 
A base principal da primeira fase consistiu no Saber Conhecer e no Saber Conviver. Nessa fase do programa foram discutidos os temas: Ambiente de Aprendizagem, Metodologia, Currículo e Avaliação. Além das reflexões referentes aos temas vinculados ao perfil do estudante do século XXI e do desenvolvimento de atividades teórico-práticas (Saber Conhecer), os professores-cursistas foram instigados a trabalhar em grupo (Saber Conviver). A carga horária para o desenvolvimento desta etapa foi de cinquenta e uma (51) horas, tempo destinado a metodologias ativas de aprendizagem e ao desenvolvimento de trabalhos colaborativos.

Em consonância com os conhecimentos prévios, as experiências e as necessidades do ambiente escolar, os professores-cursistas foram organizados em grupos de desenvolvimento e orientados a construir currículos integrados baseados em competências. Para isso, foram consideradas a realidade de cada contexto de atuação e o referencial curricular de cada secretaria de educação: municipal, estadual ou federal. O planejamento do currículo foi desenvolvido na segunda fase do curso, com cinquenta e sete (57) horas de atividades que promoveram interação, discussão e autoria colaborativa. Nessa fase, os professores se organizaram em grupos de desenvolvimento com o objetivo de alinhar objetivos de aprendizagem, metodologia e avaliação, ao mesmo tempo que integravam conteúdos curriculares de distintas áreas do conhecimento: Linguagens, Matemática, Ciências Humanas, Ciências da Natureza, no intuito de promover, na terceira fase do Programa MAES, intervenções nas escolas onde atuam. A construção do currículo foi guiada pelos quatro pilares da educação brasileira (DELORS, 2003; 2010) e pelos pressupostos da Taxonomia de Bloom (FERRAZ; BELHOT, 2010, p. 421), para auxiliar o "planejamento didático-pedagógico, a estruturação, a organização, a definição de objetivos instrucionais e a escolha de instrumentos de avaliação".

A implementação dos projetos de intervenção incide na terceira fase do Programa MAES. Essa fase teve cinquenta e quatro (54) horas de construção e desenvolvimento colaborativo de atividades pedagógicas dos professores-cursistas, sob orientação dos professores-formadores locais e online. Durante o período de implementação dos projetos nas escolas, os formadores atuaram como orientadores, com o papel de atender às necessidades de cada professor-cursista, colaborar na implementação do projeto e orientar no registro dos resultados dos trabalhos colaborativos.

Conforme previsto, na terceira fase do Programa ocorreram duas visitas técnicas com os professores-cursistas em contextos educacionais orientados pelo paradigma da 
aprendizagem centrada no estudante, no Brasil e na Finlândia. No Brasil, a visita aconteceu à escola Projeto Âncora ${ }^{3}$ no dia 05 de julho de 2017, com a participação de quarenta e dois (42) professores da região de abrangência do IFMS, campus Nova Andradina. Ressalta-se que na visita participaram alguns convidados, colegas de trabalho dos professores-cursistas do Programa MAES. Na Finlândia, a visita aconteceu no período de 20 de novembro de 2017 a 07 de dezembro de 2017, por doze professores (12), sendo três (3) formadores online, três (3) formadores locais, três (3) professores-cursistas e três (3) professores convidados. Os pilares de sustentação das atividades de imersão tanto em escolas brasileiras quanto finlandesas são o Saber Conviver e o Saber Ser.

Ainda na terceira fase do Programa MAES, os professores-cursistas elaboraram relatório das atividades com reflexões acerca do desenvolvimento da aprendizagem e apresentaram os projetos desenvolvidos em seminário organizado pelos formadores. Concomitante, o resultado parcial do Programa MAES foi apresentado no European Association for Practitioner Research on Improving Learning (EAPRIL), ocorrido em novembro de 2017, na cidade de Hämeenlinna, Finlândia, por quatro (4) formadores e um (1) professor-cursista.

\section{Considerações finais}

A experiência de construir, coordenar e colaborar no desenvolvimento do Programa MAES permitiu o surgimento de novas lentes de interpretação referentes aos desafios e possíveis caminhos para se desencadear novas "trans-forma-ções" docentes. Assumindo a posição de transformador e transformado pelo caminho percorrido com o MAES, para apresentar algumas considerações de encerramento do texto, que está longe de serem finais.

O Programa MAES fomentou a percepção de que o currículo integrado e por competência requer estar preparado para desconstruir amarras da formação escolar, constituídas e fortalecidas ao longo de todo processo de escolarização, indo da Educação infantil à pós-graduação. Período em que, implicitamente, são construídas "fôrmas" baseadas na exposição a modelos curriculares cujo núcleo é a competição e o desenvolvimento de conhecimento de nível inferior da Taxonomia de Bloom: lembrar, compreender e aplicar, apoiados principalmente no pilar do Saber Conhecer.

${ }^{3}$ Disponível em: <https://www.projetoancora.org.br/?gclid=CJO47rXGz9YCFYcGkQodRtkFFQ>. Acesso em: 20 set. 2017. 
Ao construir e desenvolver um currículo baseado em competências no contexto da Formação de Professores, na e para Educação Profissional Brasileira, a partir da experiência vivida com a imersão no contexto educacional Finlandês, foi possível compreender que para provocar transformações na Educação Profissional, faz-se necessário, e até mesmo urgente, repensar e reconstruir o núcleo de sustentação da organização escolar. De uma organização que favorece a competição em todas as relações sociais, defendemos o estabelecimento dos princípios da colaboração, que equilibra a partir das ações escolares o enfoque nos quatro saberes fundamentais à educação: Conhecer, Fazer, Conviver e Ser.

Como consequência, o enfoque em atividades escolares colaborativas pode fomentar o desenvolvimento de níveis superiores da Taxonomia de Bloom - analisar, avaliar e criar -, uma vez que esses três exigem o pensar com o outro, a partir da interação de saberes múltiplos e diversificados.

No contexto da Educação Profissional, faz-se necessário a promoção cada vez mais recorrente de projetos colaborativos no intuito de promover o Saber Conviver e o Saber Ser. Para isso, cabe aos educadores repensar e construir programas de formação de professores com novas "formas e fôrmas", tratando com o mesmo grau de importância os conhecimentos científicos e atitudinais, na promoção da formação integral do Professor.

\section{REFERÊNCIAS}

ANDERSON, L.; KRATHWOHL, D. A. Taxonomy for Learning, Teaching and Assessing: a revision of bloom's taxonomy of educational objectives. New York: Longman, 2001.

BAARTMAN, L. K. J.; BASTIAENS, T. J.; KIRSCHNER, P. A.; VAN DER VLEUTEN, C. P. M. Evaluation assessment quality in competence-based education: A qualitative comparison of two frameworks. Educational Research Review, v. 2, n. 2, 114-129, 2007.

BARBOSA, E. F.; MOURA, D. G. Metodologias ativas de aprendizagem na Educação Profissional e Tecnológica. B. Tec. Senac, Rio de Janeiro, v. 39, n.2, p.48-67, 2013.

BIGGS, J. B. Assessing learning quality: Reconciling institutional, staff and educational demands. Assessment \& Evaluation in Higher Education, v. 21, p. 5-15, 1996.

DELORS, J. Educação: um tesouro a descobrir. 8. Ed. São Paulo: Cortez; Brasília, DF: MEC: UNESCO, 2003. 
DELORS, J. Os quatro pilares da educação. In: DELORS, Jacques et al. (Org.). Educação: um tesouro a descobrir: Relatório para a UNESCO da Comissão Internacional sobre Educação para o século XXI. Brasília: UNESCO, 2010.

FERRAZ, A. P. C. M.; BELHOT, R. V. Taxonomia de Bloom: revisão teórica e apresentação das adequações do instrumento para definição de objetivos instrucionais. Gest. Prod., São Carlos, v. 17, n. 2, p. 421-431, 2010.

HUITT, W. Humanism and open education. Educational Psychology Interactive. Valdosta, GA: Valdosta State University, 2009. Disponível em:

<http://www.edpsycinteractive.org/topics/affect/humed.html>. Acesso em: 10 dez. 2017.

KOENEN, A. K.; DOCHY, F.; BERGHMANS, I. A phenomenografic anylisis of inplementation $\mathrm{f}$ competence-based education in higher education. Teaching and Teacher Education, v. 50, p. 1-12, 2015.

MARKHAM, T. Project based learning design and coaching guide: expert tools for innovation and inquiry for K-as educators. Califórinia: HeartlQ Press, 2012.

OECD. Global competency for an inclusive world. OECD Publishing, Paris, 2016. Disponível em: <https://www.oecd.org/education/Global-competency-for-an-inclusiveworld.pdf $>$. Acesso em: 12 set. 2017.

PERRENOUD, P. Construir as competências desde a escola. Porto Alegre: ArtMed, 1999.

PERRENOUD, P. Dez novas competências para ensinar: convite à viagem. Porto Alegre: ArtMed, 2000.

PERRENOUD, P. Ensinar: agir na urgência, decidir na incerteza. 2. ed. Porto Alegre: ArtMed, 2001.

\section{Como referenciar este relato de experiência:}

Conceição de Maria Cardoso COSTA; VIEIRA, Azenaide Abreu Soares. Metodologias Ativas: a experiência do curso MAES. Revista Ibero-Americana de Estudos em Educação, Araraquara, v. 13, n. esp1, p. 553-563, maio 2018. E-ISSN: 1982-5587. DOI: 10.21723/riaee.nesp1.v13.2018.11454

Submetido em: 30/10/2017

Aprovado em: 01/01/2018 